\title{
CONSIDERACIONES SOBRE 17 CASOS DE PERSISTENCIA DEL CONDUCTO ARTERIO-VENOSO, OPERADOS
}

\author{
Por los Dres. A. JOHOW, G. DUFFAU, M. NEIRA, L. BARTtLet, A. CIFUENTES \\ y A. GANTZ. \\ Hospital R. del Bjo. Cátedra de Cirugia Infantil y Ortopedia del Prof. Arnulfo Johow. \\ Cátedra de Pediatria del Prof. Artuso Scroggie.
}

\section{Introducción.}

\section{Prof. ARNULFO JOHOW.}

Nuestro servicio y cátedra del Hospital Roberto del Río está dividido, desde que hemos tenido el honor de dirigirlo, en equipos que se han hecho cargo, siguiendo las afinidades de cada cirujano, de las diferentes sub-especialidades, si se me permite esta expresión, de la Ortopedia y Cirugía de Niños.

Hoy se presenta ante Uds. nuestro equipo de la cirugía cardiovascular, que comprende, además, al internista especializado en estas lesiones, al radiólogo y al anestesista, que tienen todos papeles básicos y muy importantes que desempeñar en el tratamiento de estos enfexmos. Sin un diagnóstico preciso y sin la indicación quirúrgica derivada de este diagnóstico y sin una anestesia perfectamente bien llevada, es totalmente imposible esta cirugia.

Tenemos la suerte de contar en el Roberto del Río con la colaboración decidida del Dr. Gastón Duffau que, dicho sea de paso, ha hecho siempre el diagnóstico exacto de la lesión cardiovascular que investigaba, ayudado por el Dr. Manuel Neira, nuestro dinámico radiólogo. Además, contamos hoy en día con un anestesista magnífico y que en su afán de superarse, ha llegado a dominar bien este difícil arte.

(Trabajo presentado a la Seciedad Chilena de $\mathrm{Pe}$ diatría).
Para poder llegar a los resultados obtenidos en los 16 casos de ductus operados por nuestro equipo, se ha necesitado de una ardua labor preparatoria en la mesa de Morgagni primero y después en la sala de vivisección. Aprovecho esta ocasión para agradecer al Dr. José Donoso las facilidades que nos dió para poder operar en su servicio. No nos cansamos de aconsejar a todo cirujano que desea dedicarse a esta peligrosa, delicada y $\tan$ apasionante cirugía, hacer sus primeros pasos en el perro, animal que le permite ensayar todas las técnicas de la cirugía cardiovascular y sólo cuando domine bien la sutura de los grandes vasos en un mediastino que se mueve, estará en condiciones de abordar al enfermo.

Nuestro equipo de cirujanos, que ha hecho esta preparación minuciosa, no ha tenido que lamentar ninguna muerte en la operación del ductus. El único enfermo que falleció en nuestro servicio fué operado durante las vacaciones de verano, en ausencia del que habla y creemos que con más preparación previa en la sala de vivisección del cirujano que actuaba, seguramente este accidente no se habría producido. También nosotros tuvimos que afrontar una ruptura del ductus, el tercer enfermo que operábamos, y este accidente se debió 
exclusivamente a la falta de entrenamiento e instrumental apropiados. Afortunadamente, pudimos ligar los dos extremos del ductus que sangraba y quedó en perfectas condiciones.

Fué a causa de este accidente que resolvimos irmos a Estados Unidos, donde pudimos apreciar en todos los servicios en que se practica la cirugía cardiovascular el enorme entrenamiento en la sala de vivisección a que se someten los cirujanos correspondientes.

Se ha discutido y se discute todavía, si el ductus se debe ligar solamente o si se debe seccionar y suturar sus dos extremos. Esta discusión se suscitó a causa de un ductus ligado por Gross en Boston y que se recanalizó. Desde ese momento Gross, Potts y otros, hacen la sección y sutura del ductus. Sin embar- go, Blalock, en Baltimore, sigue haciendo la ligadura. Es indiscutible que la ligadura es una operación mucho menos peligrosa que la sección y creemos que la ligadura bien hecha con material irreabsorbible no debe permitir la recanalización. De nuestros enfermos, por lo menos, ninguno se ha recanalizado. Un vaso Iigado en pocos dias pierde su lumen y da una cicatriz firme. Es lógico pensar que en el ductus pase lo mismo.

El diagnóstico de la lesión y su indicación operatoria, como también el resultado alejado, será tratado por el Dr. Duffau. El Dr. Neira nos hablará sobre la radiología del ductus. El Dr. Cifuentes sobre lo que hemos hecho y el Dr. Barttlet nos explicará cómo debe darse la anestesia. Tiene la palabra el Dr. Duffau.

\section{Consideraciones clínicas.}

\section{Dres, GASTON DUFFAU y MANUEL NEIRA.}

El conducto arterioso o de Botal comunica la aorta, generalmente después de la salida de la subclavia, con la arteria pulmonar y constituye en el feto un desvio indispensable para la sangre que el ventrículo derecho inyecta en la arteria pulmonar. Con el nacimiento, la expansión pulmonar permite que la sangre pase en su totalidad a través de los pulmones $y$ ese conducto tan útil hasta entances, no tiene función que desempeñar y se cierra y atrofia. Cierre funcional primero y anatómico después. Cierre anatómico que en general se hace dentro del primer trimestre de la vida, pero que puede retrasarse incluso hasta el año de edad, sin constituir una cardiopatía congénita.

La sintomatología es variable. Puede ser nula en los primeros meses de la vida, en que la presión sistólica de la arteria pulmonar es similar a la de la aorta, prácticamente no hay pasaje de sangre y el ductus es mudo. Con el descenso de la presión máxima pulmonar aparece un soplo sistólico en el área de la pulmonar. En los años posteriores, jun- to con aumento de la presión sistémica, sobreviene un descenso de la presión diastólica en la arteria pulmonar y hace su aparición el soplo diastólico, que unido al componente sistólico, constituye el soplo sistodiastólico o en maquinaria, signo casi inequívoco de la persistencia del conducto de Botal. Esto no ocurre antes de los 3 ó 4 años de vida, lo que hace que el diagnóstico antes de esta edad sea muy difícil de asegurar y quien lo haga se expone a errores. Sirva de ejemplo el siguiente caso.

\section{N. B., - Obs. N 1192.}

Consulta a la edad de 1 año y 3 meses (18-1II-47). Se le hace el diagnóstico de una comunicación interventricular. Se va a provincia y la vemos por segunda vez, 4 años más tarde, el 8-I-51. Pues bien, el 12 del mismo mes se operaiba de persistencia del conducto arterfovenoso. Fl soplo sistólico se había transfonmado en un soplo en maquinaria típico.

Lo dicho anteriormente no nos hará negar la existencia en el lactante de los signos auscultatorios clásicos del ductus permeable, como lo hemos visto en dos 
ocasiones en nuestro material, convengamos sí que constituyen casos muy poco frecuentes.

Por otro lado, en el niño, el hallazgo de un soplo sistólico único en el foco pulmonar, generalmente no corresponde a un ductus y tendríamos que pensar más bien en otro defecto congénito, estrechez pulmonar de menor grado o defecto septal. Evitaremos, por lo tanto, de formular un diagnóstieo de persistencia del conducto arterioso cuando no exista el soplo típico.

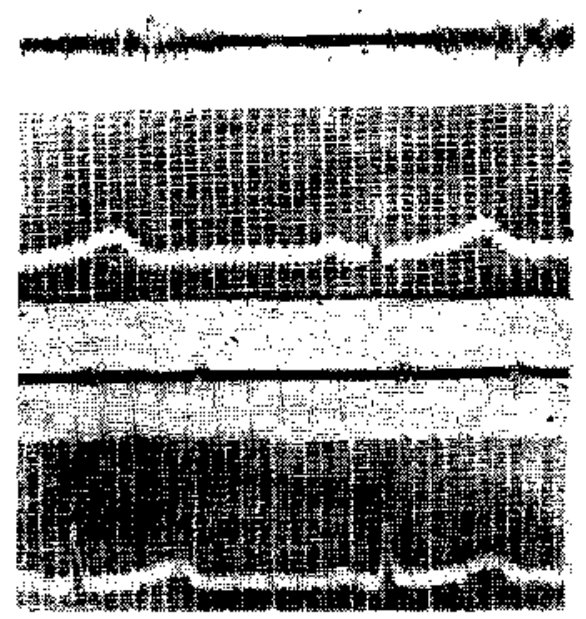

Fig. No 1. - Marta C. - 6 años.

Fonocardiograma antes y después de la intervención.

Los sintomas y signos que esta cardiopatia congénita origina, están en íntima relación con la cantidad de sangre que el ductus permeable sustrae de la circulación periférica e inyecta en la arteria pulmonar. Si el shunt es pequeño, tendremos un niño bien desarrollado, con peso y talla normal, sin ređucción de su capacidad funcional cardíaca, es decir, un niño normal si no existiera el soplo clásico. El área cardíaca está normal tanto clínica como radiológicamente.

Si el shunt es intenso, los síntomas y signos son también marcados, tanto por parte de la insuficiente circulación periférica como de la recargada circulación pulmonar. Habrá antecedentes de epistaxis a repetición, dolores a las extremidades, disnea al esfuerzo más o menos acentuada $\varepsilon$ incluso disfonia por compresión del recurrente izquierdo por la arteria pulmonar o por el ductus. Será un niño con talla y peso inferiores al normal, palidez, danza de los vasos del cue1lo, pulso saltón, pulso capilar, presión diastólica descendida, con presión sistólica normal o ligeramente aumentada. Al examen de la región precordial encontraremos un choque impulsivo de la punta, thrill sistólico o sistodiastólico de foco en el segundo y tercer espacios izquierdos propagado a la clavícula del mismo lado. Soplo continuo, en maqui-

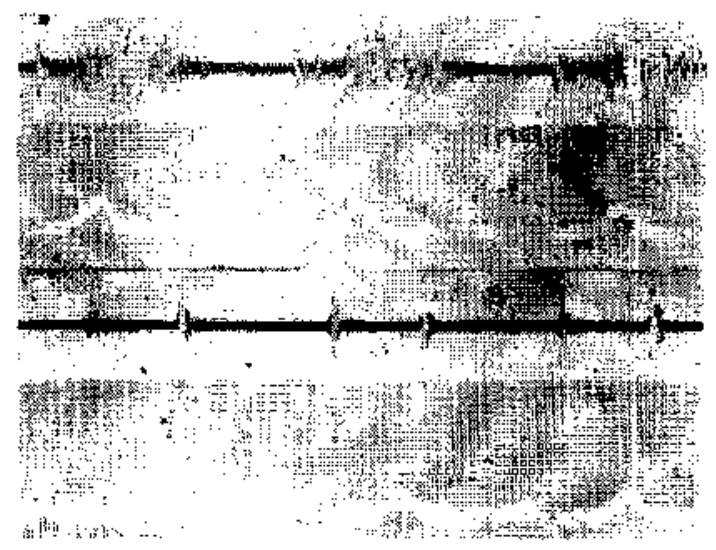

Fig. Nu 2. - Nuvia B. - 5 años. Fionocardiograma antes y después dz la intervención

naria (ruido que produce el paso de un tren a través de un túnel), soplo sistodiastólico con refuerzo ielesistólico y protodiastólico (véanse figs. 1 y 2), con reforzamiento del segundo tono en el área pulmonar. Su foco de máxima auscultación se encuentra en el segundo y tercer espacios izquierdos próximos al esternón y que se irradia a la clavicula izquierda, punta, axila, con menos frecuencia a los vasos del cuello y dorso.

El electrocardiograma es normal o con ligera desviación de QRS a la izquierda.

La radiología puede ayudarnos o no, ya que está en relación con el volumen del shunt. Cuando el circuito pulmonar está muy recargado obtendremos un aumento del área cardíaca a expensas de los dos ventrículos, pero en especial del izquierdo. Aumento $\mathrm{y}$ prominencia 
del segundo asco izquierdo o correspondiente a la arteria pulmonar. Latidos aórticos y pulmonares acentuados. Danza hiliar. Mayor densidad de los hilios y de la trama pulmonar. Velamiento de la ventana pulmonar.

El diagnóstico de esta cardiopatía congénita es en general sencillo y el uso adecuado del estetoscopio nos permitirá reconocerla rápida y seguramente en más del $90 \%$ de los casos. La anomalía congénita que con más facilidad puede confundirse con un ductus permeable es un defecto congénito del septum aórtico con comunicación entre la aorta y la arteria pulmonar. In este caso la sintomatología clínica y radiológica es similar. Podríamos decir que la localización del soplo en maquinaria no es el mismo, sino que su foco máximo está sobre el esternón y se propaga más fácilmente hacia la derecha. Además, la angiocardiografía hecha por el método retrógrado de Burford nos puede demostrar que la comunicación es más baja que la que corresponde a la persistencia del conducto arterloso, conocimiento éste de inestimable valor para el cirujano.

En general, es éste un defecto cardíaco bien tolerado en la infancia, en especial cuando el shunt es pequeño y no es asiento de una infección bacteriana subaguda. Si el volumen sanguíneo que pasa a través del ductus es de consideración, la circulación periférica se resiente $\mathrm{y}$ en buen porcentaje de los casos se retarda el desarrollo físico del niño. El corazón aumenta su débito, doblando de esta manera su trabajo, Io que acarrea un aumento de sus cavidades $\mathrm{y}$ una disminución de sus reservas vitales, lo que, a su vez, puede ocasionar la falla cardíaca.

El pronóstico del ductus persistente era, hasta hace poco, muy incierto. En el niño semeja una cardiopatía inocua, ya que es rara la insuficiencia cardíaca propiamente tal, lo mismo que la infección bacteriana; pero en el adulto el pronóstico es serio y al decir de Keys y Shapiro, el individuo que alcanza a la edad de 17 años tiene la mitad de expectativa de vida que el resto de la población.
Les acecha la falla cardíaca y en no menos del 25 al $53 \%$ de los casos (Bullock, Jones, Dolley) la endoarteris y endocarditis bacteriana subaguda. El aneurisma y la ruptura del ductus es menos frecuente $(6 \%)$.

Hoy el pronóstico es tatalmente otro, gracias a la cirugía.

Es indudable que el niño hipotrófico, el niño con cardiomegalia o signos de falla cardíaca, lo mismo que el niño con una endarteritis bacteriana subaguda, deben operarse. En el primer caso bastará, en lo posible, mejorar el estado general. Reposo y tónicos cardíacos cuando hay signos de insuficiencia cardíaca y tratamiento previo con antibióticos si hay infección bacteriana. En este caso el cirujano debe darmos un plazo prudencial para entregarle el enfermo libre de su infección. Si el germen es resistente al tratamiento médico, debe intervenir la cirugía. Dicho de otro modo, los enfermos infectados deben tratarse en forma intensa; lograda la esterilización sanguínea, lo entregamos al cirujano, y si el médico no consigue su objetivo, debe operarse aún en período activo.

Además de estos enfermos que tienen indicación operatoria por nadie puesta en duda, existe un buen número de niños con un pequeño shunt, y por lo tanto sin síntomas subjetivos ni objetivos (aparte del soplo), en los que la urgencia de la intervención puede ser discutida. Tiempo atrás se rıos preguntó en este mismo recinto, si este tipo de niño debe operarse o no, y contestamos entonces que un ductus diagnosticado como tal debe operarse siempre: Es indudable que para que esta aseveración sea correcta, es indispensable contar con un equipo de cirujanos expertos en esta clase de intervenciones $y$ que, por lo tanto, nos den el máximo de seguridad postoperatoria. Son entonces dos las condiciones absolutamente necesarias: una de orden médico y otra de orden quirúrgico, un diagnóstico clínico correcto $y$ un cirujano experto.

No enviaremos a la mesa de operaciones al enfermo que no tenga los síntomas y signos clásicos de ductus, espe- 
cialmente el soplo típico. Si solamente existe el soplo sistólico y aunque la radiología y el electrocardiograma nos sugieran fuertemente el diagnóstico de conducto de Botal persistente, no lo entregaremos al cirujano, porque es seguro que éste encontrará otras anomalías y no la persistencia del conducto arterioso. Es en estos enfermos en donde la an. giocardiografía retrógrada y en especial el sondeo cardíaco nos puede ayudar. Si la sonda pasa del ventrículo derecho a la arteria pulmonar y de aquí a la aorta a la altura de la salida de subclavia, el diagnóstico es inobjetable.

Por otro lado, si la clínica quirúrgica no nos da una seguridad razonable, es preferible dejar estos enfermos a su suerte, siempre que no podamos enviarlo a un cirujano competente en esta materia.

De ahí nuestra conducta con la serie de 16 enfermos enviados por nosotros a la mesa operatoria. En los primeros la indícación quirúrgica era perentoria, había hipotrofia y sobre todo signos de fala cardíaca. En los últimos, subjetivamente asintomáticos, contábamos ya con la experiencia quirúrgica necesaria.

Somos decididos partidarios de la intervención profiláctica. Es de ejecución más sencilla y de éxito prácticamente seguro en relación con aquélla efectuada en un corazón con insuficiencia cardíaca $o$ en un ductus infectado.

La edad óptima para intervenir está entre los 4 y 15 años, mejor aún entre los 6 y los 12 años.

Finalmente, no constituye contraindicación operatoria la concomitancia con defectos septales, con lesiones inactivas de la válvula mitral o con estenosis pulmonar valvular. Estos corazones son beneficiados con la oclusión quirúrgica del conducto arterioso.
Nuestra serie está compuesta de 16 enfermos, más 1 enviado de un Hospital de adultos, afecto de una endoductitis bacteriana: 3 hombres y 14 mujeres. Lo habitual es la manifiesta predominancia femenina. El menor de 4 años, el mayor de 18 años. Se distribuyen así: de 0-5 años, 2; de 5-10 años, 10; de 10-15 años, 4; más de 15 años, 1 . El área cardíaca estaba aumentada en 11 , en 3 de ellos se agregan signos de insuficiencia cardíaca congestiva. En 6 el corazón era prácticamente normal en tamaño y forma. Estado nutritivo deficiente en 7. La presión diferencial estaba aumentada en 16.

En todos, el ductus persistente era una malformación cardíaca única. Con catarata congénita (ya operada) 2 enfermos, no habia antecedentes de rubeola. Un caso con síndrome de Wolf-ParkinsonWhite, síndrome que no se modificó con el cierre quirủrgico del ductus.

Sometidos a la intervención quirúrgica, 15 de ellos han seguido control en el Servicio de Cardiología, control que en el primer caso lleva ya $21 / 2$ años y en el último, 6 meses. Los síntomas cardiovasculares descritos desaparecieron en todos. En algunos, durante el primer tiempo, se auscultó un soplo sistólico en el área pulmonar, que posteriormente desapareció. El tamaño cardíaco se hizo normal, cuando estuvo aumentado, haciéndolo en último término el segundo arco izquierdo. La actividad física volvió a lo normal. En los que había hipotrofia, ésta tiende a desaparecer y en algunos, como la primera enferma operada, niña de 11 años de edad, en quien el complejo de inferioridad hacía presa de ella, ha desaparecido; su vida ahora es la de una niña normal y su talla más baja, hasta hace $2 \frac{1}{2}$ años que su hermana menor, tiende ya a sobrepasarla; ha aumentado $11 \mathrm{~kg}$ de peso y $14 \mathrm{~cm}$ de talla. 


\title{
Consideraciones sobre anestesia.
}

\author{
Dr, LUIS BARTTLET.
}

El gran problema que se presenta al anestesista en las operaciones intratorácicas es el neumotórax quirúrgico. La abertura de la pleura parietal conduce al colapso pulmonar brusco, por acción de la presión atmosférica. Esto trae consigo una serie de complicaciones más o menos graves en la fisiología pulmonar, tales como: muerte brusca, el bamboleo mediastínico, la respiración pendular o interpulmonar, el entorpecimiento de la función hematósica del pulmón opuesto y obstáculo en la circulación menor, que puede llevar a la fatiga cardíaca por anoxia y asfixia.

La evolución de la anestesiología, desde los estudios iniciales de Sauerbruch, que crearon los métodos de presiones diferenciales, hasta los modernos aparatos de anestesia en circuito cerrado y la incorporación de las técnicas de intubación traqueal, ha hecho factible muchas intervenciones endotorácicas, siendo la más reciente de éstas la Cirugía Reparadora de las Cardiopatias Congénitas.

Estas operaciones crean al anestesista algunos problemas anestésicos especiales para cada una de estas malformaciones. A continuación expondremos aquéllos referentes a las operaciones de ductus arterio-venosos efectuadas en nuestra clínica.

Premedicación: Los pacientes que poseen esta lesión presentan una hipoxia relativa, que se ve agravada por cualquiera excitación, psíquica o física. De aquí que sean los requisitos más importantes de una correcta medicación preoperatoria, la depresión metabólica al máximo y la sedación psiquica completa. Esto se realiza con el empleo de barbitúricos, opiáceos y derivados de la belladona.

Los barbitúricos y la morfina producen sedación general, reducen el metabolismo e inducen al sueño.

La atropina disminuye las secreciones de las vias respiratorias, previene los síncopes producidos por la hiper-excitabilidad del nervio vago, pues provoca su sección fisiológica. Experimentalmente se ha demostrado que esta hiperexcitabilidad vagal conduciría al paro cardíaco, mediante un reflejo que tiene punto de partida en las terminaciones nerviosas de las vías aéreas al ser estimuladas. Lo que no ocurre si previamente se ha atropinizado.

Respecto a las dosis de morfina y atropina hemos seguido lo preconizado por la Dra. Taussig, que indica dosis relativamente altas, las cuales son muy bien toleradas por los niños, incluso lactantes de pocas semanas.

A todos nuestros enfermos se les administró la noche antes un barbitúrico, de preferencia Nembutal, que le permitió pasar una noche tranquila.

Al día siguiente, una y media hora antes de iniciar la anestesia, una nueva dosis de Nembutal, y una hora antes morfina y atropina por vía subcutánea, en dosis apropiada a la edad.

Con esta premedicación se permite una inducción anestésica suave, sin defensa del enfermo y una vez conseguido un plano anestésico profundo se obtiene un ritmo respiratorio tranquilo, que favorece la acción del cirujano.

Elección del agente anestésico y técnica: Al considerar este punto, hay que tener presente los requerimientos del enfermo y del cirujano.

a) Para el paciente: permitir una inducción suave y tranquila, con alta proporción de oxígeno, asegurar una adecuada ventilación, con vías respiratorias permeables, libres de secreción mucosa, que permita una rápida reexpansión del pulmón colapsado, cuando las circunstancias lo requieran, remoclón del $\mathrm{CO}^{2}$ y que altere lo menos posible la fisiología pulmonar.

b) Para el cirujano otorgar un campo operatorio quieto, no perturbado por 
los movimientos respiratorios excesivos $\mathrm{y}$ forzados.

Los anestésicos usados han sido siempre: Inducción con ciciopropano, gas, que permite una inđucción rápida y sin períodos de excitación, además que por su gran poder narcótico puede ser administrado con altas concentraciones de oxigeno.

Se continúa la anestesia con una mezcla de Eter-Oxígeno en "Circuito Cerrado en Círculo" en niños mayores de 6-7 años y en circuito cerrado según la técnica "To and fro" en niños menores. La mascarilla usada debe ser lo más pequeña posible, para disminuir al máximo el espacio muerto, o mejor aún, haciendo la conexión directa a la cánula traqueal, con lo cual se consigue mejor este objetivo. Reinsuflación pulmonar cada 20-30 minutos, lavando con suero y suave masaje sobre la superficie pulmonar para evitar atelectasias.

Para disminuir al máximo la excitabilidad vagal, instalamos en el momento de iniciar la operación una fleboclisis con una solución de Novocaína al $1 / 2 \times 1,000$ en suero glucosado a razón de 20 gotas por minuto. No hemos tenido accidentes de esta naturaleza.

La intubación traqueal en niños pequeños o lactantes puede ocasionar algunas complicaciones, que van desde la tos, hasta el edema laríngeo, que puede necesitar traqueotomía.

Dada la gran variabilidad de calibre, de la glotis y de la longitud entre ésta y la bifurcación traqueal, incluso en niños de una misma edad, hay que tener cuidado especial al elegir la cánula. Su calibre debe ser el mayor que sea posible sin producir lesiones de las cuerdas vocales, para evitar el escape de aire entre la pared de la cánula y la tráquea.
Su longitud debe también ser adecuada, no muy corta, para evitar su salida de la laringe; ni muy larga, que se introduzca en uno de los bronquios, generalmente en el derecho (1 caso en nuestra estadística).

Delicadeza, cuidadosa selección de un tubo suave, de tamaño adecuado, y más que nada, experiencia, son las normas para una buena intubación traqueal, que de por sí es difícil en el nin̄o por las razones anteriormente expuestas.

Para lograr un silencio completo del campo operatorio y evitar el vaivén del mediastino, que es en el niño, al contrario del adulto, muy movible, es necesario llevar la anestesia hacia un plano muy profundo y peligroso para el enfermo.

Afortunadamente, la introducción de una nueva droga, el curare, en el campo de la anestesiología moderna, ha solucionado este problema.

La acción del curare se manifiesta a nivel de la placa neuro-motora, elevando el umbral a los estímulos de la acetilcolina y produciendo, por lo tanto, una gran relajación de musculatura esquelética, sin necesidad de llevar al enfermo a una narcosis profunda.

Su uso en anestesia pediátrica es muy reciente; de ahí que sólo lo empezamos a usar en la segunda mitad de nuestros enfermos, con resultados altamente halagadores, permitiéndonos abolir totalmente los movimientos respiratorios espontáneos, que quedan a voluntad del anestesista y con gran complacencia del cirujano.

Se lleva un atento control: del ritmo respiratorio, pulso y presión. Es importante destacar el alza de la presión mínima en el momento de la ligadura del ductus. 


\title{
Técnica quirúrgica en el ductus.
}

\author{
Dres. ALFREDO CIFUENTES y ALFREDO GANTZ.
}

Entregado el paciente en condiciones para la intervención, por el anestesista, se le coloca en decúbito lateral derecho, con el brazo izquierdo levantado $y$ un cojín bajo los hombros.

La incisión que mejores resultados nos ha dado es una a nivel del $4^{\circ}$ espacio intercostal izquierdo, desde el esternón hasta la región costo vertebral (circunscribiendo la mama si es mujer), sin resección costal. Algunos la emplean a nivel del $3^{9}, 5^{\circ}$ ó $6^{\circ}$ espacio con o sin resección costal. En algunos enfermos nosotros también las usamos, pero $\sin$ mayores ventajas. Actualmente, los autores recomiendan una incisión posterolateral, que dicen ser suficiente. No creo que la empleada por nosotros tenga inconvenientes; el campo que nos ofrece es suficiente y los resultados alejados sin secuelas.

Debe hacerse una muy buena hemostasis para, además de evitar la pérdida de sangre, que en este tipo de incisiones puede llegar a ser considerable, impedir que ella caiga a la cavidad toráxica. Abierta la pleura, se colapsa el pulmón. desprendiendo o seccionando las adherencias pleuropulmonares, que no es raro que existan y nos aparece después de colocado el separador de tórax, la imagen siguiente: en el fondo del campo operatorio veremos con toda facilidad $y$ nitidez (cuando no ha habido alguna irritación pleural que como secuela deja un engrosamiento pleural) el nervio frénico hacia adentro, el vago hacia afuera, y haciendo eminencia a través de la pleura mediastínica la aorta y la arteria pulmonar, hacia arriba la subclavia. Nos ha tocado con suma frecuencia apreciar un ganglio entre la aorta y la arteria pulmonar, precisamente en el sitio de ubicación del ductus. el cual. además, se aprecia muy bien por el treehl característico.
Se incinde la pleura mediastínica a $1 \mathrm{~cm}$ por dentro del vago y en una extensión de 5 a $7 \mathrm{~cm}$; paralelo a él disecamos las hojas pleurales, tomándolas con dos hilos. Para facilitarnos el trabajo ubicamos el nervio recurrente que, saliendo del vago, pasa por debajo del ductus y que debemos respetar. Disecamos y extirpamos el ganglio cuando existe y nos entregamos a la tarea de liberar el ductus del tejido que lo rodea; es el momento culminante de la operación, ya que cualquier descuido, endurecimiento o fragilidad de las paredes del ductus, nos ilevará a su ruptura y hemorragia casi siempre fatal. No es raro que el tejido que envuelve el ductus sea duro, fibroso, difícil de disecar por fenómenos inflamatorios, sean pleurales o de ductitis. Para facilitar este tiempo operatorio los autores han ideado instrumentos apropiados que permitan una rápida y eficaz aislación (Pinzas de Potts de diferentes grados de curvadura, espátulas de Finochietto, tijeras finas con filo en sus dos lados, todos de mango largo).

Una vez aislado por sus cuatro caras el ductus, se aconseja ocluirlo con una pinza para apreciar los cambios de presión, pulso $u$ otras alteraciones del enfermo.

En un comienzo sólo se ligaba, con doble amarra, colocando o no entre ellas una substancia esclerosante. Como algunos casos se recanalizaron y tuvieron que reoperarse, se trató, cuando esto era posible, de seccionarlo entre dos pinzas, haciendo una sutura corrida de sus extremos y aun una ligadura de refuerzo en ambos muñones. Posteriormente, las estadísticas han demostrado que un ductus bien ligado no se recanaliza nunca y es por esto que, nosotros empleamos sólo una doble ligadura y en algunos casos cuando disponía- 
mos, de una tercera ligadura al medio de aponeurosis de gato, con resultados hasta ahora excelentes.

Una vez que tenemos el ductus bien aislado, pasamos un hilo grueso empapado en glicerina, para que lo levante y procedemos a colocarle las dos amarras de hilo mediano. Para estar seguros de que los nudos no se nos puedan correr, atamos los cabos con una amarra de seda fina. Terminado esto se sutura la pleura mediastínica con puntos de catgut separados (algunos ni siquiera la hacen), dejamos $100,000 \mathrm{U}$ de penicilina disueltas en $1 \mathrm{~cm}$ de suero en el lecho del ductus ligado. Aseo de la cavidad pleural con suero y sutura de la pared por planos, dejando un drenaje (sonda de Malecot) a nivel del $6^{\circ}$ ó $7^{\circ}$ espacio intercostal y en la línea axilar posterior.

No conviene mantener colapsado el pulmón más de media a tres cuartos de hora y si la intervención se prolonga deberá suspenderse una o dos veces para distenderlo.

Aspiradas las secreciones bronquiales se traslada el enfermo a la sala de postoperados, donde se conecta el drenaje al aparato de aspiración permanente, de 10 a $12 \mathrm{~cm}$ de agua, durante 24 a 48 horas, según el derrame y la ventllación pulmonar, controlados a rayos. Si no hay complicaciones el enfermo puede levantarse al $3^{9}$ ó $4^{\circ}$ día.

En un comienzo usábamos la cámara de oxígeno a permanencia, pero con frecuencia tenfamos neumonías o bronconeumonías, por lo que la abandonamos para estos enfermos, por no ser necesaria y empleando, en aigunos casos, la oxigenoterapia por sonda o mascarilla cuando era necesaria.

Como tratamiento postoperatorio: penicilina, estreptomicina y calmantes de diversos tipos.

Se describen como complicaciones en esta operación: la hemorragia por fragilidad de las paredes del ductus, pleuresias serosas, parálisis de los miembros superiores por compresión axilar durante la operación, parálisis cardíacas brus- cas atribuidas a una alta concentración de $\mathrm{CO}^{2}$ en el aire alveolar o a irritación vagal. En los casos operados con infección bacteriana, se suelen ver temperaturas por algunos días. De nuestros enfermos hemos tenido que lamentar el fallecimiento de uno por excesiva fragiIidad del ductus. En otro, la ruptura de él y que afortunadamente se pudo tomar y llevar a término la operación y 2 ó 3 casos de bronconeumonía, que cedieron rápidamente a la terapia.

\section{Resumen.}

Se hacen consideraciones clínicas, de diagnóstico, de anestesia y de técnica quirúrgica en relación con 17 eniermos operados de persistencia del conducto arterio-venoso. El diagnóstico se basó en la presencia del soplo tipico de esta mal conformación cardíaca, además de los signos periféricos. El electrocardiograma fué normal o con ligera desviación izquierda.

En los primeros casos operados hubo signos de falla cardíaca y fué ésta la que decidió la intervención. Los últimos se enviaron a la mesa operatoria con el fin de efectuar una intervención profiláctica. Fueron 3 hombres y 14 mujeres, el menor de 4 años y el mayor de 18 años. En todos el ductus persistente era una malformación cardíaca única. Con catarata congénita bilateral 2 enfermos. Un niño con síndrome de Wolff-Parkinson-White.

Se relata la evolución post-operatoria, destacando la vuelta a la normalidad de la silueta cardíaca cuando ésta estuvo aumentada, lo mismo que la capacidad física del niño y la normaltzación de la talla y peso cuando hubo hipotrofia.

La técnica anestésica usada en los 17 casos fué la siguiente: premedicaciôn con barbitúricos (nembutal), atropina $y$ morfina en dosis proporcionadas a su edad y siguiendo las indicaciones de la Dra. Taussig. Anestesia en circuito cerrado según la técnica to and fro en menores de 7 años y en circulo en niños mayores, con intubación oro-traqueal $y$ baronarcosis. Inducción con ciclopropano y mantenimiento con eteroxígeno. Ad- 
ministración de curare endovenoso y novocaína al $1 / 2 \times$ mil con suero glucosado al $5 \%$ en fleboclisis a razón de 24 gotas por minuto. Sangre y suero glucosalino según necesidad.

Toracotomía izquierda a nivel del $4^{\circ}$ espacio intercostal, en los primeros casos con resección subperióstica de la cuarta costilla. Se hace notar la presencia casi constante de un ganglio situado junto al ductus. Individualizado éste, se hizo en todos los casos sólo ligadura, con resultados satisfactorios. De rutina se indicaron antibióticos durante los primeros días.

\section{Summary.}

Clinical, diagnostic, anesthetic and surgical technic considerations are made in a study of 17 cases operated on for persistance of the ductus arteriosus. The diagnosis was based on the presence of a typical murmur plus the peripheral signs. The electrocardiogram was normal or had a slight left axis deviation.

In the first cases operated on there were signs of heart failure and this was what decided the operation. The last patients operated on were for profilactic reasons. There were 3 boys and 14 girls, the youngest 4 years old and the oldest 18. In all cases the ductus was the only congenital heart malformation. Two patients had congenital bi- liateral cataracts. One child had a Wolff-Parkinson-White syndrom.

The post operative course is detailed, stressing the normalization of the heart shadow when this was increased, as well as the physical capacity and normalization of height and weight when these were under average.

The anesthetic technic used in the 17 cases was the following: barbituric (nembutal) premedication, atropin and morfin in doses proportional to their age and following Dra. Taussig's indications. Closed circuit anesthesia using the to and fro technic in those younger than 7 years of age and in circle in all the children, with orotracheal intubation and baronarcosis. Induction with ctclo and maintenance with ether-oxygen. Administration of intravenous curare and 1 half per thousand novocaine in $5 \%$ glucose, intravenously at the rate of 24 droppes per minute. Blood and glucose and saline solutions if needed.

A left theracotomy at the level of the fourth intercostal space with a subperiostic resection of the fourth rib. They stress the nearly always constant presence of a lymph gland adjacent to the ductus. Once this was individualized, in all cases only a ligature was done with satisfactory results. As a routine measure all post operated cases received antibiotics. 